\title{
Risks of modern biotechnologies and legal aspects of their implementation in agriculture
}

\author{
F. T. Nezhmetdinova ${ }^{1, *}, M$. E. Guryleva ${ }^{2}, N$. Kh. Sharypova ${ }^{1}, R . I$. Zinurova $^{3}$, and A. R. Tuzikov ${ }^{3}$ \\ ${ }^{1}$ Kazan State Agrarian University, 420015 Kazan, Russia \\ ${ }^{2}$ Kazan State Medical University, 420012 Kazan, Russia \\ ${ }^{3}$ Kazan National Research Technological University (KCTI), 420015 Kazan, Russia
}

\begin{abstract}
The main purpose of this study is to determine the best practices of social regulation of negative consequences for modern biotechnology use based on a comparative review of European and Russian legal regulations on food safety. The paper gives original classification of risks of biotechnologies introduction in agriculture, namely: food, agricultural, environmental, patent, social and ethical ones. Although risk assessment systems have been in use for some time, consumers do not always trust the results. One explanation for this is that in the past many national food safety systems had problems with timely notification of certain products' potential hazards. In many countries, social and ethical views can be the reason for rejection of certain products, manipulation of genetically modified organisms (GMOs). Such conflicts often reflect deeper issues about the interaction of human society and nature - issues that must be fully taken into account in any attempt at social communication. Authors offer a mode of social control and consensus in the form of agrobioethics, similar to bioethics in biomedical technologies.
\end{abstract}

\section{Introduction}

Global challenges, strategic socio-economic priorities of the future of Russia and its regions determined acceleration of the study, forecasting and development of tools that should contribute to sustainable development of rural areas, ensure safety and quality of life, protect the environment and improve environmental management. The Rome Declaration of World Food Security Summit between 13 - 17 November 1997 defined food security as: "ensuring that all people have access at all times to the food they need for a healthy and active life."

In the 21 st century agriculture faces many challenges: it must produce more food, fodder and dietary fiber for a growing population with fewer rural workers, more raw materials for a potentially larger bioenergy market, contribute to overall development in agriculture-dependent developing countries, adopt more efficient and sustainable production methods as well as adapt to climate change.

Food security from the viewpoint of any state is the ability of the state regardless of external and internal threats to meet the needs of the population in food in volumes, quality and assortment that correspond to accepted standards and safety regulations [1].

Key issues:

1. "Is our food safe in terms of application of new biotechnologies?"
2. "What measures should be taken in terms of convergence of global food market to standardize approaches, regulation and to provide consumer safety"?

Main problems of food safety

1. Low-income citizens must choose cheap (often counterfeit) and low-quality food.

2. A trend of general decline in the quality of all food and increasing levels of anxiety towards food production with using genetic engineering.

3. Increase in the flow of genetically modified foods/organisms (GM foods/ GMOs) and products from them: soybeans, corn, canola, rice, potato, pumpkin, papaya, etc.

4. Extension of intellectual property rights to genetically modified breeding and seed material by large trans-national corporations (TNCs).

5. Low level of awareness of both farmers and consumers about food safety standards.

6. A large number of international and domestic legal regulations (more than 300).

7. Complexity of harmonizing requirements to ensure competitiveness and high food safety standards.

Use of modern technologies in living systems (and agriculture is a set of living systems) raises questions of risks and security, as it is associated with dual-use sciences [2].

In modern scientific literature, this issue has long been given increased attention [3-5].

* Corresponding author: nadgmi@mail.ru 


\subsection{International policies and standard systems for food safety: brief overview}

In 2005, within the international program for future development of the Organization for Economic Cooperation and Development, a project was launched: "Prospects for Development of Bioeconomy by 2030". Main preconditions for bioeconomy development on a global scale are:

population growth, its income per capita and educational level, primarily in developing countries, where, according to forecasts in $2030,97 \%$ of 8.3 billion inhabitants of the planet will live;

increased energy demand coupled with the need for measures to reduce greenhouse effect;

ageing of the population in the EU, BRIC countries, as well as growing need for food, thus, to produce it transgenic plants and animals will be used.

At the international level, the World Trade Organization (WTO) is responsible for developing regulations on food hygiene and safety. The agreement on sanitation and phytosanitary (SPE-agreement), concluded by WTO members, includes a wide range of activities related to the protection of people and animals from diseases associated with use of food products. EU legislation reflects its obligations to the World Trade Organization (WTO) and complies with requirements of the Codex Alimentarius Commission where appropriate [6].

European legislation on food products can be divided into following three main components. Food products safety legislation that covers such areas as hygiene of food products, food additives, materials in contact with food products, new types of food products, as well as control systems. The second family of laws relates to information for consumers, which is mainly presented on labels. The third family of laws establishing quality requirements is aimed at protecting quality and includes "vertical" directives, i.e. directives for dairy products, dietary products and specific products produced in certain regions [7-12].

Over the past 15 years, new approaches and new principles of the international system of standards for food safety have been developed, namely:

1. The principle of "from farm to table (farm-totable)" - a systematic approach that controls parameters of food safety at all stages of production - from obtaining raw materials to consuming product by the end user. The farm-to-table concept is an integrated food and fodder quality control system that is traceable at all stages of food production and delivery. Safe foods are foods that do not pose a risk to human and animal health.

2. The principle of "Traceability" in the chain of fodder and food production. "Traceability" is a systematic approach that controls parameters of food safety at all stages of production - from obtaining raw materials to consuming product by the end user.

The Codex Alimentarius and HACCP system are main mechanisms for ensuring the quality and safety of food in the WTO $[13,14]$.
Russian legislation in the field of food safety has the following structure and quantitative parameters:

1. In the field of veterinary supervision $(39,10$ of them are Federal Laws).

2. In the field of phytosanitary surveillance (36, 5 of them are Federal Laws).

3. In the field of safe handling of pesticides, agrochemicals and seed control $(25,3$ of them are Federal Laws)

4. In the field of protection of consumer rights and environment (22, 3 of them are Federal Laws)

In total: more than 120 basic legal documents, not counting technical regulations and sanitary rules.

\subsection{Development of modern biotechnologies and risks of implementing in agriculture}

Advances in biology, biochemistry, breeding, genetics, microbiology mean a real revolution in agriculture - a biotechnological one. Its achievements are manifested in new means of production, unconventional technologies as components of zonal systems of agriculture, genetic engineering.

Nanotechnology and genetic modification are two tools that experts on agricultural production growth put their greatest hopes on. Gene or genetic engineering is fundamentally different from breeding, dealing with methods of creating varieties and hybrids of plants, crops and animal breeds.

The task of genetic engineering is to obtain desired qualities of a modified or genetically modified organism. Unlike traditional breeding, in which the genotype is changed only indirectly, genetic engineering allows direct intervention in genetic apparatus, using the technique of molecular cloning. When introducing new genes into an organism (it can be a plant, an animal, a microorganism or a person), it is possible to give it a new desirable characteristic, which it has never possessed before. Genetically engineered organisms are called GMOs (genetically modified organisms) [15].

One of the important tasks of genetic engineering in agriculture is to obtain plants resistant to viruses, since currently there are no other ways to combat viral infections of crops. Introduction in plant cells of genes of virus's shell protein makes plants resistant to this virus. Currently, scientists have obtained transgenic plants capable of resisting the effects of more than a dozen different viral infections. Another important task of genetic engineering is related to the protection of plants from insect pests. Application of genetic engineering in agriculture has reduced the use of insecticides by 40 $60 \%$.

In other words, as a result, production of genetically modified organisms (GMOs) can increase crop yields and intensify the productivity of farm animals. All of this increases opportunity to solve the world's food problem and becomes a way to reduce food prices.

However, the use of GMOs, despite wide and rapid spread, is a natural concern. While some experts do not deny the enormous potential of agricultural 
biotechnology in the production of foods, they warn that benefits of biotechnology should not be overestimated and that its potential negative effects should not be overlooked in determining its role in global agricultural production.

Scientists fear that use of biotechnology-derived seeds could lead to a loss of genetic diversity among crops, as native species can be replaced in the same way that modern hybrids have replaced many traditional varieties or breeds. Moving towards genetic homogeneity can lead to a greater susceptibility of plants to many pests, diseases or other negative environmental impacts, problems that are the scourge of monoculture agriculture. There are also ethical problems associated with transformation and introduction of genes of one species of plants or animals into the genetic apparatus of another species [16].

European Group on Ethics noted the need for an integrated perspective and approach to agricultural technologies to ensure that ethical assessments of the effects of new technology take into account production, storage and distribution. Such basic goals as food security, food safety and duration of use (permanence) in its opinion should be adopted as main priorities and principles to which every technology in agriculture should be aligned.

Any technological modification, including changes in the genetic basis of plants or animals used for food, can cause resistance from the society. While goals of food security, in its narrowest sense, are clearly articulated and agreed at the international level, goals of nature protection, environmental safety and sustainable agriculture are much more complex, unclear and vary depending on the features of a particular region.

The public is not strongly opposed to GMOs, people discuss the arguments both "for" and "against" and are aware of contradictions associated with them. They also do not require a complete absence of risk, as they understand their life is associated with a large number of risks that need to be balanced against each other and potential benefits.

Systematizing the risks that GMOs can provoke, we can offer their classification. The basis for the classification is the level of possible harm and safety for key components of the food market: food products, environment, agriculture, consumer health, the right to change and to possess new natural objects. This classification of risks can be used to develop measures to prevent the impact of possible threats from the introduction of GMOs in agriculture. The following types of risks can be distinguished:

\section{Food risks:}

$>\quad$ Direct effect of toxic and allergenic transgenic GMO proteins.

$>$ Risks mediated by pleiotropic effect of transgenic proteins on plant metabolism.

$>$ Risks mediated by accumulation of herbicides and their metabolites in resistant varieties and species of agricultural plants.

$>$ Risks of horizontal transfer of transgenic structures, primarily in the genome of symbiotic bacteria for humans and animals (E. coli, Lactobacillus (acidophillus, bifidus, bulgaricus, caucasicus), Streptococcus thermophilus, Bifidobacterium, etc.).

\section{Environmental risk:}

$>$ Reduction of varietal diversity of crops due to the mass use of GMOs derived from a limited set of parent varieties.

Uncontrolled transfer of structures, especially those determining different types of resistance to pesticides, pests and plant diseases, due to overpollination with wild related and ancestral species. In this regard, reduction of biodiversity of wild ancestral forms of cultivated plants and formation of "super weeds".

Risks of uncontrolled horizontal transfer of structures into rhizosphere microflora.

$>$ Negative impact on biodiversity through affection of non-target insects and soil microflora with toxic transgenic proteins as well as violation of trophic chains.

\section{Agronomic risks:}

unpredictable changes in non-target properties and characteristics of modified varieties associated with pleiotropic effect of introduced gene. For example, reduced resistance to pathogens during storage and reduced resistance to critical temperatures during vegetation in varieties resistant to insect pests.

$>$ delayed changes in properties, after several generations, associated with adaptation of a new gene in the genome and with manifestation of both new pleiotropic properties and changes already declared.

$>\quad$ ineffectiveness of transgenic resistance to pests after several years of mass use of this variety.

$>$ the possibility for producers to use terminal technologies to monopolize seed production.

\section{Patent risks}

Six years ago, "Monsanto" Company sued 75-yearold Indiana farmer Hugh Vernon Bowman for violating a seed patent and won. But the farmer did not leave the matter and in late February 2013, filed a lawsuit in the U.S. Supreme court.

As of January 2013, "Monsanto" Company filed 144 lawsuits against 410 farmers in 27 States. According to the report released by the CFS (Center for Food Safety), over the years, "Monsanto" has been spending huge resources to "watch" and sue farmers: 75 employees and a special budget since 2003 - $\$ 10$ million a year. Authors of the report also indicate that by the end of 2012, "Monsanto" received more than $\$ 423.5$ million dollars for patent infringement from farmers and agricultural enterprises.

\section{Social risk:}

growth of unfair distribution of income of a certain producer of agricultural products and an owner of patents for modern biotechnology.

$>$ reduced quality of food and its availability.

\section{Ethical risks:}

$>$ use of biotechnological seeds may result in the loss of genetic diversity of crops.

$>$ moving towards genetic homogeneity can lead to a higher susceptibility of plants to many pests, diseases or other negative environmental impacts. 
there are ethical problems associated with transformation and introduction of genes of one species of plants or animals into the genetic apparatus of another species [16].

\subsection{Agrobioethics as a tool for bioethical examination of social implications and modern risks of bioeconomy}

At the same time it is congruent with the general social context, when the last quarter of the 20th century and the early of the 21 st century gave rise to such a specific phenomenon, which German sociologist Ulrich Beck called "other modern" or "society of risk " [17]. As P. D. Tishchenko notes, specificity of social context of biotechnologies is historically uncertain, when science and society, social phenomena and people constantly test themselves in attempts at self-identification and, thus, they constantly change, becoming different [18]. These changes result in "constellations of possibilities", which offer a person a choice of a certain development line from a variety of possible paths. As V. S. Stepin emphasizes, in these conditions this very choice is irreversible and most often unambiguously cannot be calculated. [18]. And here, rightly, in our opinion, emphasis is made to change the meaning and use of the concept of "risk", which, firstly, from the category of personal space only moves to the global level. Secondly, if in the previous century the risk was considered as a result of insufficient development of technologies and scientific knowledge, today the risk arises where there is an excess of technological and scientific progress [19].

Comprehension of these risks brings us closer to understanding the increasing relevance of humanitarian expertise in the form of bioethics. Now, bioethics, on the one hand, is a recognized scientific field of interdisciplinary knowledge, subject of which is evaluation and selection of moral criteria of attitude to the living (the definition belongs to the author - F. T.). On the other hand, it is a social practice approved by the world community of ethical regulation of scientific research and, first, clinical research, introduction of modern NBIC technologies in the economy and production $[19,20]$.

It is also necessary to work towards the most consistent ethical assessment of use of modern food biotechnology and GM foods. This will help in the analysis of risks and benefits to human health and the environment, assessment of socio-economic factors, including intellectual property rights, as well as in the consideration of ethical aspects. As a consequence, the demand for bioethics experience will increase, its social significance will intensify and new forms will appear $[21,22]$. Agrobioetics may become one of such directions of its development, it is understood as a mechanism of social control and regulation of new "material viability" in bioeconomics.

Agrobioetics is a new approach to resolving ethical dilemmas that may arise in everyday application of new technologies in agriculture. It involves dispute resolution skills, emotional intelligence, interpersonal and social communication for resolving disputes between producers and consumers of agricultural products, as well as between the state and civil society. The goal is to reach a consensus focused on health and safety of a consumer, accepted by all parties involved, and that is consistent with the laws and principles of bioethics.

\section{Data and methods}

This study used the analysis and review of international and Russian normative legal acts regulating standards and norms of food safety in terms of bioeconomics development. The following methods were used: system analysis, historical retrospective, comparative analysis.

\section{Results and discussion}

Over the past three years, imports of genetically modified products to Russia have tripled. But in most cases, they are claimed to be products of "natural origin". According to the Institute of Nutrition, in 1998, there were sporadic cases of GMOs use in food production. However, currently the Russian market is experiencing a real expansion of genetically modified products. According to the Russian legislation, products containing $5 \%$ or more of GMO components must be properly labeled. But many manufacturers do not follow the law. One of the main reasons for this is lack of a control system over the use of GMOs in food in Russia. There are no laboratories in the country capable of assess quantitatively GMO content in food to the required extent; there are no approved methods, and there are no means for continuous monitoring. As a result, consumers suffer: they do not have all the necessary information about the food they purchase.

According to the Institute of Nutrition and Research Institute of Meat Industry, currently in Russia there are no standardized methods of quantitative measurement of GMOs in finished foods. Authorized laboratories of Sanitary and Epidemiological Services can only conduct qualitative analysis of food.

Given the global nature of development of bioeconomics agricultural sector, international cooperation in the field of legal and ethical regulation of development and implementation of biotechnology is of particular relevance today [23-26].

Advantages of implementing international food safety standards are as follows:

$\checkmark \quad$ it provides consumers with the necessary guarantees for food safety;

$\checkmark \quad$ recognition by consumers;

$\checkmark \quad$ achieving greater compliance with international requirements, which is especially important in terms of the WTO;

$\checkmark \quad$ use of world experience in the field of food safety management systems;

$\checkmark \quad$ transition to a new level of production culture, thinking and labor discipline;

$\checkmark \quad$ foreseeing potential threats to product safety and application of preventive measures, instead of belated actions to correct defects and recall products; a 
systematic approach that controls the parameters of food safety ("from farm to table principle");

$\checkmark$ reducing the costs associated with manufacturing defects;

$\checkmark \quad$ expansion of product sales market, including its sale in foreign markets;

$\checkmark \quad$ additional competitive advantages in tenders;

$\checkmark \quad$ increase in investment attractiveness;

$\checkmark \quad$ build-up of reputation for the producer of highquality and safe food;

$\checkmark \quad$ increasing suppliers' confidence and advantages in getting orders from other companies.

Discoveries made in recent years in the field of biosciences are perceived by experts as convincing proof that the 21 st century will be the era of biotechnology, which, in combination with nanotechnology and bioinformatics, will radically change existing approaches to the creation, production and consumption of products, and ultimately form the foundation for sustainable growth on a global scale, for complex changes in the economy, society and politics. At the same time, they give rise to legitimate concerns in terms of safety for human health and the environment [27]. First of all, it applies to genetic engineering, which can carry certain risks. For Russian consumers such risks are complicated with the following circumstances:

$>$ Russia adopted documents in the field of legal regulation of GMO production later than in the European Union.

$>$ There is no Federal law regulating GMOs in our country. There are not enough trained GMO supervisors.

There is no broad professional discussion of GMOs in the medical community.

$>$ Existing documents in the Russian Federation do not provide for a mandatory large-scale and long-term study of the safety of GMOs, as well as environmental consequences of the GMOs use.

$>\quad$ It should be added that the existing regulatory framework provides for a deliberate legal bias towards the interests of GMO producers.

At the same time, from our point of view, there are positive trends. Thus, Federal law of the Russian Federation of 1996 N86 "On state regulation of genetic engineering" in Art. 5. presents main directions of state regulation in the field of genetic engineering.

Also, in July 2016, Federal law N358-FZ was adopted "On amendments to certain legislative acts of the Russian Federation in terms of improving state regulation in the field of genetic engineering", which banned cultivation and breeding of genetically modified plants and animals.

The purpose of the amendments is to improve state regulation in the field of genetic engineering. In particular, they introduced control over the release of genetically engineered modified organisms (hereinafter GMOs) into the environment, as well as monitoring the impact on humans and the environment of GMOs and products obtained with the use of such organisms or containing them. It is forbidden to grow and breed genetically modified plants and animals in the country. The exception is if they are used to carry out examinations and research works. Importers of GMOs and related products were encharged to undergo necessary registration procedures.

The Russian government has the right to prohibit import of these organisms and products into Russia according to monitoring results. In addition, there is administrative liability for use of GMOs and (or) products obtained from their use or containing GMOs without state registration, if it is required by law, or certificate validity of state registration of which has expired. It involves a fine: for officials - from 10 thousand to 50 thousand rubles, for organizations - from 100 thousand to 500 thousand rubles.

A similar sanction is provided for the use of GMOs in violation of the permitted type and conditions of application. The Federal law enters into force from the date of its official publication, except for certain provisions for which other terms are established.

\section{Conclusion}

It becomes obvious that it is necessary to involve additional tools, such as agrobioetics, in the analysis and formation of safety assessment standards to implement modern technologies in agriculture. The conflict of rights and interests of producers and consumers of GMOs is the main problem of agrobioetics related to GMOs. In the discussion of positive and negative sides of GMO technologies, one should not give in to emotions and draw unfounded conclusions, accusing biotech companies of "profiting from human grief" or trying to destroy natural ecosystems and "turn the earth into a desert". However, we must remember that uncontrolled use of such powerful techniques can really lead to negative consequences, and it is necessary, as in any issue, to find some "golden mean". Independent experts - scientists and government officials - should be involved in controlling activities of biotechnology companies; work on creation and introduction of genetically modified crops to the market should be covered in detail in the press, since often the fear of GMOs arises solely because of poor public awareness and has no real basis.

The practice existing in modern democratic societies shows that these discussions are absolutely necessary not only for fuller understanding of all "pluses" and "minuses" of application of methods invading personal life already at the level of genetics. They also provide an opportunity to discuss moral and ethical aspects and to determine long-term consequences of biotechnology use, which in turn enables legislators to create an adequate legal framework governing this sphere in order to protect the rights of the individual. It is possible to create Ethical committees on agrobioetics, similar to ethical committees in the field of medical clinical research. Considering global nature of bioeconomy development, international cooperation in the field of legal and ethical regulation of biotechnology development and implementation is of particular relevance today. In this cooperation an important place belongs to bioethics, which has accumulated significant positive experience of interdisciplinary dialogue and practice. 


\section{References}

1. A.L. Kovtun, D. L. Polonskaya, Analysis of the significance of technology in modern consideration of problems of biological safety Molecular medicine 5, 1-8 (2012)

2. Alex Dubov, The concept of governance in dual-use research Medicine, Health Care and Philosophy 17(3), 447-457 (August 2014)

3.D.R.J. Macer, Biotechnology in Agriculture: Ethical Aspects and Public Acceptance 661-90 (New York, 1997)

4.D.R.J. Macer, Shaping Genes: Ethics, Law and Science of Using Genetic Technology in Medicine and Agriculture (Eubios Ethics Institute, Christchurch, 1990)

5. D. Suzuki, P. Knudtson, Genethics: The Clash Between the New Genetics and Human Values (Harvard University Press, Boston, 1989)

6. Global Challenges and Directions for Agricultural Biotechnology: Workshop Report. National Research Council (US) Steering Committee on Global Challenges and Directions for Agricultural Biotechnology: Mapping the Course (Washington (DC), National Academies Press (US), 2008)

7. Advisory Committee on Releases to the Environment (ACRE) Report 1: Towards an evidence based system for regulation of GMOs (Government of UK, 2013) Retrieved from: https://www.gov.uk/government/uploads/system/upl oads/attachment_data/file/239839/an-evidencebased-regulatory-system-for-gmos.pdf

8. Commission of the European Communities (EC). (2000) White paper on food safety (COM (1999) 719 final) (Brussels, European Commission, 2000) Retrieved from: http://ec.europa.eu/transparency/ regdoc/rep/1/2001/EN/1-2001-493-EN-F1-1.Pdf

9. EU Council. Regulation 178/2002: Laying down the general principles and requirements of food law, establishing the European Food Safety Authority and laying down procedures in matters of food safety (2002) Official J. of the European Communities Retrieved from: https://www.fsai.ie/uploadedFiles/ Legislation/Food_Legisation_Links/General_Princip les_of_Food_Law/Consol_Reg178_2002.pdf

10. European Parliament and EU Council. Regulation 852/2004: On the hygiene of foodstuffs Official J. of the European Communities (2004) Retrieved from: https://www.food.gov.uk/sites/default/files/multime dia/pdfs/enforcement/feedhygregengqa.pdf

11. European Commission. Regulation 16/2011: Laying down implementing measures for the Rapid alert system for food and feed Official J. of the European Communities (2011) Retrieved from: https://publications.europa.eu/en/publication-detail//publication/ae47f50e-4247-4aee-a169$\mathrm{d} 228 \mathrm{dbde} 324 \mathrm{c}$

12. EC. 2012a. Rural development in the European
Union. Statistical and economic information report (European Commission, Directorate General for Agriculture and Rural Development, Luxembourg, 2012)

13. European Parliament and EU Council. Regulation 882/2004: On official controls performed to ensure the verification of compliance with feed and food law, animal health and animal welfare rules Official J. of the European Communities (2004) Retrieved from: http://eur-lex.europa.eu/legalcontent/EN/ALL/?uri=CELEX\%3A32004R0882

14. E. Garcilazo, Modern Rural Development Policies in OECD Countries "Urban Rural Partnerships for Sustainable Development: Experience of the Baltic Sea Region" (27 October 2014) Retrieved from: http://forumstrategov.ru/

15. N.A. Abdallah, C.S. Prakash, A. McHughen, Genome editing for crop improvement: Challenges and opportunities GM Crops \& Food 6(4), 183-205 (2015)

16. A. McHughen, A critical assessment of regulatory triggers for products of biotechnology: Product vs. process GM Crops Food 7(3-4), 125-158 (2016)

17. U. Beck, Risk society. On a way to another modern (Sage, London, 1999)

18. P. D. Tishchenko. The phenomenon of bioethics Questions of philosophy 3, 104-113 (1992)

19. F. Nezhmetdinova, Global challenges and globalization of bioethics Croat Med J. 54(1), 83-85 (February 2013) doi: $10.3325 / \mathrm{cmj} .2013 .54 .83$ (2013).

20. F. Nezhmetdinova et al., Global challenges for agrarian sector of Russian economy and it human resources Revista ESPACIOS 39(26) (2018)

21. P. D. Tishchenko, To the beginnings of bioethics Questions of philosophy 3, 62-75 (1994)

22. V.R. Potter, Bioethics: Bridge to the future (Englewood Cliffs, N/J.: Prentice-Hall, 1971)

23. Reports OECD. Looking to 2060: Long term growth prospects world (2012) Retrieved from: https://www.oecd.org/eco/outlook/2060\%20policy\% 20paper\%20FINAL.pdf

24. B. Van der Meulen, The structure of European food law Laws 2, 69-98 (2010)

25. D. Sadik, K. Ulbricht, N. Djamankulov, Control system of food safety in the European Union and the Eurasian economic Union Trade policy 2(6), 41-84 (2016)

26. OCED. The Bioeconomy to 2030: designing a policy agenda. Int. Futures Programme (2009) Retrieved from: http://www.oecd.org/futures/bioeconomy/ 2030

27.R. Johnston, Analysis of future-oriented technology: the problem of Cassandra Foresight 2(5), 58-64 (2011) 